\title{
HUBUNGAN ANTARA KEPUASAN KERJA DENGAN \\ KUALITI PERKHIDMATAN DALAMAN STAF MAJLIS SUKAN NEGERI-NEGERI DI MALAYSIA
}

\section{THE RELATIONSHIP BETWEEN JOB SATISFACTION AND SERVICES QUALITY AMONG MALAYSIAN STATES SPORTS COUNSIL STAFF}

\author{
Phylicia Phoa Siew Ching ${ }^{1}$ \\ Fakulti Psikologi dan Pendidikan, Universiti Malaysia Sabah (UMS), Malaysia. \\ (Email: charissaphylicia@yahoo.com) \\ Mohamad Nizam Nazarudin ${ }^{2}$ \\ Unit Penyelidikan Pendidikan Luar Bandar, Fakulti Psikologi dan Pendidikan, \\ Universiti Malaysia Sabah (UMS), Malaysia. \\ (Email: drnizam.ums@gmail.com)
}

Received date: $24-04-2019$

Revised date: 03-07-2019

Accepted date: 17-07-2019

Published date: 15-09-2019

To cite this document: Phoa, S. C. P., \& Nazarudin, M. N. (2019). Hubungan Antara Kepuasan Kerja Dengan Kualiti Perkhidmatan Dalaman Staf Majlis Sukan Negeri-Negeri Di Malaysia. International Journal of Education, Psychology and Counseling, 4 (32), 119-129.

DOI: $10.35631 /$ IJEPC.4320012

\begin{abstract}
Abstrak: Kajian ini bertujuan untuk mengenal pasti hubungan antara kepuasan kerja dengan kualiti perkhidmatan dalaman dikalangan staf Majlis Sukan Negeri-Negeri di Malaysia. Responden kajian ini telah dipilih menggunakan kaedah persampelan berperingkat yang terdiri daripada 155 orang staf Majlis Sukan Negeri-Negeri di Malaysia. Kajian ini merupakan kajian kuantitatif bukan eksperimen yang menggunakan instrumen soal selidik. Data kajian dianalisis menggunakan perisian Statistical Package for Social Sciences (SPSS) versi 20. Kepuasan kerja dan kualiti perkhidmatan dalaman adalah pada tahap yang tinggi. Terdapat hubungan positif yang tinggi dan sangat kuat serta signifikan antara kepuasan kerja dengan kualiti perkhidmatan dalaman. Dapatan kajian menunjukkan bahawa dengan adanya kajian ini maka pihak pengurusan dapat menfokuskan kepada elemen atau aspek kepuasan kerja yang diyakini mampu mempengaruhi kualiti perkhidmatan dalaman dalam sesebuah organisasi dan juga prestasi sesebuah organisasi tersebut.
\end{abstract}

Kata Kunci: Kepuasan Kerja, Kualiti Perkhidmatan Dalaman, Majlis Sukan Negeri

Abstract: This study aimed to identify the relationship between job satisfactions with quality of internal services among staff State Sports Council in Malaysia. Respondents were selected 
using a staged sampling consisting of 155 Majlis Sukan Negeri-Negeri Malaysia staff. This research is non-experimental quantitative research using survey instruments. Data analyzed using Statistical Package for Social Sciences (SPSS) version 20. Job satisfaction and quality of service is at a high level. There was positive and very strong significant relationship between job satisfaction with internal service quality. The findings show the management can focus on elements or aspects of job satisfaction, which is believed capable of affecting the quality of internal services in an organization as well as the performance of the organization.

Keyords: Job Satisfaction, The Quality Of Internal Services, The State Sports Council

\section{Pengenalan}

Kebanyakkan organisasi akan bersaing untuk memberikan perkhidmatan yang berkualiti tinggi bagi meningkatkan prestasi organisasi mereka (Porsoltani \& Iraji, 2012). Perkhidmatan dalaman merujuk kepada perkhidmatan yang diberikan kepada pekerja manakala perkhidmatan yang diberikan kepada pelanggan pula dikenali sebagai perkhidmatan luar. Perkhidmatan konsisten disediakan untuk memenuhi jangkaan pengguna (Ghorbani, 2014).

Aspek penting dalam kualiti perkhidmatan dalaman adalah untuk melihat bagaimana pekerja divisyen menyediakan perkhidmatan kepada rakan-rakan mereka kerana kualiti perkhidmatan dalaman dan memberi kesan kepada kepuasan kerja (Zhen You, 2003). Meng Xia (2003) dalam kajiannya menegaskan bahawa perkhidmatan dalaman yang berkualiti tinggi akan meningkatkan kepuasan pekerja, yang secara tidak langsung akan mewujudkan kepuasan pelanggan luaran dan meningkatkan prestasi organisasi. Liang Wang (2010) percaya bahawa dengan memberi tumpuan kepada kualiti perkhidmatan dalaman, ianya merupakan titik permulaan bagi kepuasan pelanggan, pihak berkepentingan, dan pelanggan luaran seterusnya meningkatkan prestasi organisasi.

Sebelum menumpukan perhatian kepada pasaran luaran dan pelanggan, sesebuah organisasi tersebut perlu memfokuskan diri mereka sebagai pasaran dalaman dan pekerja sebagai pelanggan dalaman (Barnes \& Morris, 2000). Perhatian terhadap intra-organisasi dapat memberikan impak terhadap kepuasan pelanggan dalaman dan luaran yang akan mungkin menjamin kejayaan sesebuah organisasi. Perkhidmatan dalaman juga merupakan elemen yang membantu dalam mencapai perkhidmatan luaran yang berkualiti tinggi. Oleh itu, kualiti perkhidmatan dalaman ini perlu dikaji keberkesannya khususnya dalam bidang sukan (Amirtash \& Mozaffari, 2012).

Yue Xia (2009) melaporkan bahawa kualiti perkhidmatan dalaman dan kepuasan pelanggan dalaman menyumbang kepada kepuasan pelanggan luaran, yang akhirnya mempengaruhi pertumbuhan organisasi dan keuntungan. Chelladuraie (2003) turut menyatakan bahawa perkhidmatan dalaman yang ditawarkan kepada pekerja juga boleh mempengaruhi kualiti perkhidmatan yang ditawarkan kepada pelanggan luar, justeru memberi kesan ketara kepada prestasi organisasi. Oleh itu, pengurusan sumber manusia perlu mempunyai strategi yang mampan untuk menghasilkan pekerja yang cemerlang kerana ia merujuk kepada cara dan pendekatan yang digunakan oleh organisasi untuk mengurus dan mengawal aktiviti yang berkaitan dengan sumber manusia dalam organisasi agar selari dan mencapai matlamat organisasi (Faridahwati et al., 2006). 


\section{Penyataan Masalah}

Pengarah dalam bidang sukan lazimnya memahami bahawa perkhidmatan yang berkualiti dan kepuasan pelanggan merupakan kunci kepada kejayaan sesebuah organisasi (Chelladurai, 2003). Oleh itu, kajian lanjut untuk mengenalpasti sama ada kepuasan kerja merupakan salah satu faktor yang mempunyai hubungan dengan kualiti perkhidmatan dalaman bagi organisasi Majlis Sukan Negeri perlu dilaksanakan. Hal ini kerana, berdasarkan ulasan daripada latar belakang kajian, dapat dilihat bahawa kualiti perkhidmatan dalaman dan kepuasan kerja adalah elemen penting yang wujud dan saling berinteraksi dalam organisasi sukan untuk membentuk sebuah organisasi yang efisien dari segi perkhidmatan lantas meningkatkan prestasi sesebuah organisasi tersebut.

Antara faktor lain yang mendorong pengkaji untuk mengkaji pembolehubah ini adalah, Ramseook-Munhurrun et al., (2010) dalam kajiannya mendapati bahawa kebanyakkan perkhidmatan awam gagal untuk memenuhi harapan dan keperluan pelanggan. Selain itu, Die Xie (2005) turut menegaskan bahawa lazimnya organisasi sukan hanya berusaha untuk menilai kualiti perkhidmatan dari sudut pandangan pelanggan luaran sahaja tetapi tidak melihat kepada kualiti perkhidmatan dalaman dan interaksi antara pekerja. Keadaan ini adalah amat membimbangkan khususnya bagi perkhidmatan awam yang menyediakan perkhidmatan kepada pelanggan kerana kualiti perkhidmatan yang lemah akan mempengaruhi kepercayaan pelanggan dan jumlah pelanggan luaran justeru secara tidak langsung akan menggangu prestasi sesebuah organisasi tersebut.

Berdasarkan permasalahan ini, ianya telah mendorong pengkaji untuk meneliti dan melaksanakan kajian untuk menerangkan hubungan dan faktor yang mempengaruhi kualiti perkhidmatan dalaman dalam organisasi Majlis Sukan Negeri agar kualiti dan prestasi organisasi tersebut dapat dipertingkatkan dan mutu organisasi sukan adalah pada tahap yang lebih baik.

\section{Objektif Kajian}

Kajian ini bertujuan untuk mengkaji hubungan antara kepuasan kerja dengan kualiti perkhidmatan dalaman staf Majlis Sukan Negeri-negeri di Malaysia. Objektif kajian ini adalah untuk:

i. Mengenal pasti tahap kepuasan kerja staf di Majlis Sukan Negeri-negeri di Malaysia.

ii. Mengenal pasti tahap kualiti perkhidmatan dalaman staf di Majlis Sukan Negerinegeri di Malaysia.

iii. Mengenal pasti hubungan antara kepuasan kerja dengan kualiti perkhidmatan dalaman di majlis Sukan Negeri-negeri di Malaysia.

Hipotesis Nol

Ho1: Tidak terdapat hubungan yang signifikan antara kepuasan kerja dengan kualiti perkhidmatan dalaman.

\section{Kajian Literatur}

\section{Kepuasan Kerja}

Kepuasan kerja dapat didefinisikan sebagai penzahiran rasa seronok, selesa, dan tenteram atau perasaan positif yang terhasil daripada pengalaman kerja atau suatu sikap yang terhasil daripada kepuasan emosi individu terhadap pekerjaannya (Fatimah Affendi, 2014). Menurut Lee et al., (2007), kepuasan kerja boleh digunakan sebagai penilaian yang luas terhadap sikap penerimaan keseluruhan pekerja dalam sesebuah organisasi, kepuasan dan keseronokan pekerja dalam perlaksanaan kerja mereka. 
Kepuasan kerja ini juga melibatkan perasaan positif atau negatif seseorang terhadap pekerjaannya. Kepuasan kerja merujuk kepada tahap kepuasan pekerja dalam kalangan organisasi ini terhadap pekerjaan dan persekitaran kerja mereka (Fatimah Affendi, 2014).

Kajian lanjutan yang dibuat ke atas kepuasan kerja terhadap organisasi adalah perlu dan antara faktor yang patut dipertimbangkan dalam pelaksanaan kajian ini adalah faktor dalaman seperti autonomi, penghargaan dan tanggungjawab. Manakala, antara faktor luaran yang harus dipertimbangkan adalah persekitaran fizikal, penyeliaan, waktu bekerja dan upah. Kedua-dua aspek ini harus memenuhi jangkaan dan keperluan individu dalam mencapai kepuasan kerja dalam organisasi.

\section{Kualiti Perkhidmatan Dalaman}

Frederick dan Mukesh (2001) menjelaskan kualiti perkhidmatan dalaman adalah merujuk kepada persekitaran dalaman berdasarkan kesedaran untuk memberi sokongan dalam kalangan pekerja dan kakitangan sokongan termasuk pengurusan dan lain-lain dalam penyediaan perkhidmatan sokongan. Konsep kualiti perkhidmatan dalaman dalam kajian ini adalah dicirikan daripada sikap manusia antara satu sama lain dan cara individu berkhidmat antara satu sama lain di dalam sesebuah organisasi. Menurut Large dan Konig (2009), kualiti perkhidmatan dalaman merupakan pra syarat untuk prestasi keseluruhan syarikat.

Kualiti perkhidmatan dalaman ini merupakan diskripsi kerja yang jelas untuk meningkatkan kesedaran staf terhadap isu kualiti, prodiktiviti, kepuasan pelanggan dan kepercayaan terhadap perkhidmatan sesebuah organisasi tersebut (Gotzami dan Tsiotras, 2002). Oleh itu aspek ini perlu ditiitkberatkan oleh sesebuah organisasi yang menitikberatkan mutu perkhidmatan kerana dipercayai kualiti perkhidmatan dalaman ini mampu meningkatakan operasi dalaman syarikat dan mutu komunikasi bagi pelanggan dalaman serta luaran.

Hallowell \& Schlesinger dan Zornitsky (1996) mencadangkan bahawa kualiti perkhidmatan dalaman adalah berkait rapat dengan kualiti perkhidmatan pelanggan. Dapatan kajian ini turut menyokong tanggapan bahawa kepuasan kerja dikaitan dengan kepuasan kerja terhadap kualiti perkhidmatan dalaman berbanding kepuasan terhadap upah dan faedah.

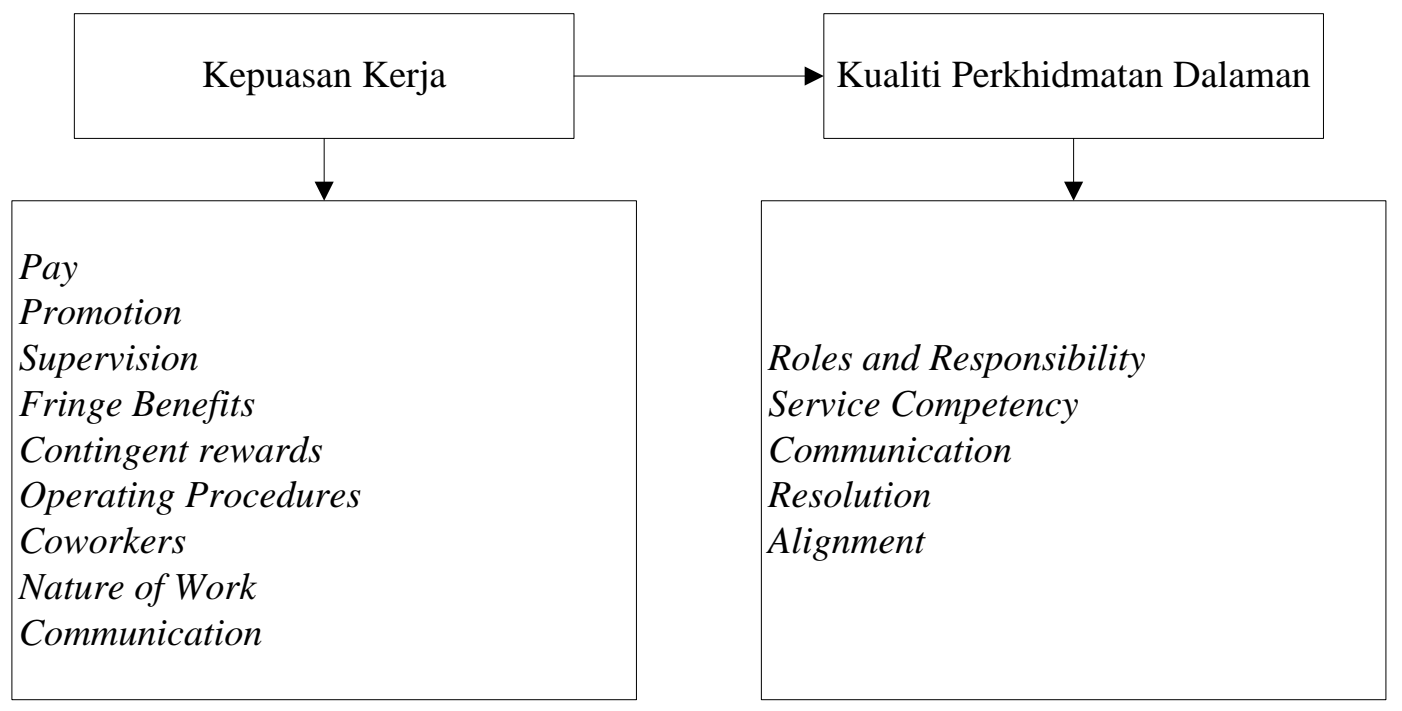

Rajah 1: Hubungan Antara Kepuasan Kerja Dengan Kualiti Perkhidmatan Dalaman 


\section{Kepuasan Kerja dan Kualiti Perkhidmatan Dalaman}

Para pengkaji kini mendapati bahawa transformasi corak pemikiran organisasi kini lebih peka terhadap kualiti perkhidmatan yang disediakan. Perkara ini khususnya difokuskan melalui pekerja dengan menganggap pekerja sebagai pelanggan dalam sesebuah organisasi tersebut. Oleh itu aspek seperti kepuasan kerja yang juga berkait rapat dengan kualiti perkhidmatan dalaman juga telah dibincangkan oleh pengkaji terdahulu seperti Gilbert, 2000; Gunawardane, 2009; Hallowell, Schlesinger, \& Zornitsky, 1996; Heskett, Sasser, \& Schlesinger, 1997; Jun \& Cai, 2010; Kuei, 1999; Marshall, Baker, \& Finn, 1998; Miguel, Salomi, \& Abackerli, 2006b; Pantouvakis, 2011.

Beberapa kajian emperikal telah membuktikan bahawa terdapat hubungan yang positif antara kualiti perkhidmatan dalaman dengan kepuasan kerja (Back, Lee, \& Abbott, 2011; Panjakajornsak, 2012; Pantouvakis, 2011). Menurut MCManus, Keeling dan Paice (2004), dengan menyediakan kualiti perkhidmatan yang berkualiti kepada pelanggan dalaman iaitu pekerja mampu mempengaruhi kepuasan kerja yang akhirnya juga akan membawa kepada keberkesanan dan kecekapan serta kualiti kerja.

Keupayaan berkhidmat seseorang pekerja bergantung kepada kualiti proses dalaman, sumber yang ada dan juga pengiktirafan (Newman, Maylor \& Chansarkar, 2001). Perkara ini mempengaruhi kepuasan kerja pekerja dan secara tidak langsung juga memberi kesan kepada kerelaan seseorang pekerja tersebut untuk terus kekal dalam sesebuah organisasi tersebut dalam jangka masa yang panjang dan kualiti perkhidmatan yang ditawarkan. Dalam masa yang sama perkara ini turut akan mempengaruhi kepuasan pelanggan luaran yang menerima perkhidmatan yang ditawarkan serta keuntungan serta keberkesanan sesebuah organisasi tersebut.

Daud (2010) yang mendapati bahawa gaji juga turut mempengaruhi tahap kepuasan kerja ahli organisasi. Semakin tinggi gaji yang diterima, maka semakin tinggi tahap kepuasan kerja seseorang itu kerana terdapat perkaitan antara sistem ganjaran dan pencapaian individu (Yusoff, 2012). Ganjaran merupakan pemangkin untuk menggalakkan individu terus berusaha bekerja dengan lebih bersemangat dan lebih baik serta membuatkan diri seseorang itu dihargai dan merasa kewujudannya serta hasil kerjanya diiktiraf oleh organisasi disamping sebagai tanda sokongan organisasi kepada pekerjanya. Sokongan daripada organisasi sangat perlu kerana ianya dapat meningkatkan kepuasan kerja pekerja (Adey \& Bahari, 2010).

Kepuasan kerja adalah peramal yang penting bagi kedua-dua individu dan prestasi organisasi. Kajian empirikal menunjukkan bahawa kepuasan kerja yang tinggi menyumbang kepada tahap komitmen organisasi, kepuasan hidup dan penglibatan kerja yang lebih baik (Lok dan Crawford, 2004). Kepuasan kerja yang tinggi juga mampu mengurangkan ketidakhadiran, niat perolehan, tekanan kerja dan pembuangan pekerja (Griffin et al., 2010; Sagie, 1998). Keadaan ini secara tidak langsung turut mempengaruhi kualiti perkhidmatan dalaman dalam sesebuah organisasi. Kesimpulannya, dapatan kajian lepas kukuh membuktikan bahawa kepuasan kerja ini mampu memberi impak kepada para pekerja untuk bekerja dengan lebih gigih dan positif dan dalam masa yang sama juga akan mempengaruhi prestasi organisasi.

\section{Metodologi Kajian}

Kajian ini merupakan kajian yang berbentuk kuantitatif bukan eksperimen yang menggunakan instrument soal selidik. Soal selidik yang digunakan adalah berdasarkan instrument Job satisfaction survey (JSS) yang diubahsuai daripada Spector (1994) dan soal selidik Internal Service quality scale (INTQUAL) oleh Caruana dan Pitt (1997 diubahsuai 
oleh Cook, 2004). Skala likert 7 mata digunakan untuk setiap item soal selidik. Kajian ini telah dilaksanakan di Majlis Sukan Negeri-negeri di Malaysia dengan saiz populasi kajian seramai 249 orang staf Majlis Sukan Negeri-negeri di Malaysia yang bergred S19 dan ke atas sahaja. Bagi memenuhi tujuan persampelan rawak kelompok ini, rumus Krejcie dan Morgan (1970) telah digunakan sebagai dasar untuk melihat jumlah sampel iaitu menerusi jumlah populasi kajian. Menurut rumus tersebut, saiz sample adalah dalam lingkungan 148-152 orang responden. Jumlah populasi yang pengkaji gunakan adalah seramai 155 orang.

\section{Dapatan Kajian}

Kepuasan Kerja dan Kualiti Perkhidmatan Dalaman Staf Majlis Sukan Negerinegeri di Malaysia

Jadual 1.0 menunjukkan analisis dan huraian ringkas demografi responden. Demografi responden dalam kajian ini melibatkan beberapa aspek seperti jantina, umur dan tahun pengalaman bekerja.

\section{Jadual 1: Taburan Demografi Responden Staff Majlis Sukan Negeri-Negeri Bergred S19 Dan Ke Atas.}

\begin{tabular}{lll}
\hline Ciri-ciri responden & Frekunsi & Peratusan (\%) \\
\hline Jantina & & \\
Perempuan & 75 & $48.4 \%$ \\
Lelaki & 80 & $51.6 \%$ \\
Umur & 70 & \\
30 tahun dan ke bawah & 47 & $45.2 \%$ \\
31-40 tahun & 31 & $30.3 \%$ \\
41-50 tahun & 7 & $20.0 \%$ \\
T1 tahun dan ke atas. & & $4.5 \%$ \\
Tahun Pengalaman Bekerja & 26 & $16.8 \%$ \\
Kurang daripada 1 tahun & 45 & $29.0 \%$ \\
1-5 tahun & 51 & $32.9 \%$ \\
5-10 tahun & 33 & $21.3 \%$ \\
10 tahun ke atas &
\end{tabular}

Jadual 2.0 menunjukkan keputusan skor min bagi kepuasan kerja $(\min =5.80)$ dan kualiti perkhidmatan dalaman $(\min =5.91)$ di Majlis Sukan Negeri-negeri di Malaysia. Skor min ini menunjukkan bahawa ianya berada pada tahap yang tinggi.

Jadual 2: Keputusan Skor Min Bagi Setiap Variable Kajian

\begin{tabular}{cccccc}
\hline & $\mathrm{N}$ & Minimum & Maximum & Min & $\begin{array}{c}\text { Sisihan } \\
\text { Piawai }\end{array}$ \\
\hline $\begin{array}{c}\text { Kepuasan Kerja } \\
\text { Kualiti Perkhidmatan } \\
\text { Dalaman }\end{array}$ & 155 & 5.06 & 6.53 & 5.8030 & .27382 \\
& 155 & 5.05 & 6.57 & 5.9115 & .27158 \\
\hline
\end{tabular}

Hubungan antara Kepuasan Kerja dengan Kualiti Perkhidmatan Dalaman

Jadual 3.0 menunjukkan Pekali Korelasi Pearson bagi hubungan antara kepuasan kerja dengan kualiti perkhidmatan dalaman adalah $r=.817$. Ini menunjukkan bahawa terdapat 
hubungan positif yang sangat kuat dan sangat signifikan antara kepuasan kerja dengan kualiti perkhidmatan dalaman staf Majlis Sukan Negeri-negeri di Malaysia. Keputusan Ujian Korelasi Pearson adalah, $\mathrm{r}(155)=.817, \mathrm{p}<.01$. Oleh itu, Ho1, Tidak terdapat hubungan yang signifikan antara kepuasan kerja dengan kualiti perkhidmatan dalaman adalah ditolak.

\section{Jadual 3: Hubungan Antara Budaya Pembelajaran Organisasi Dengan Kualiti Perkhidmatan Dalaman}

\begin{tabular}{|c|c|c|c|}
\hline & & $\begin{array}{c}\text { Kualiti Perkhidmatan } \\
\text { Dalaman }\end{array}$ & $\begin{array}{c}\text { Budaya Pembelajaran } \\
\text { Organisasi }\end{array}$ \\
\hline \multirow{3}{*}{$\begin{array}{c}\text { Kualiti Perkhidmatan } \\
\text { Dalaman }\end{array}$} & Korelasi Pearson & 1 & $.817^{* *}$ \\
\hline & Sig. (2-tailed) & & .000 \\
\hline & $\mathrm{N}$ & 155 & 155 \\
\hline \multirow{3}{*}{$\begin{array}{c}\text { Budaya Pembelajaran } \\
\text { Organisasi }\end{array}$} & Korelasi Pearson & $.817^{* *}$ & 1 \\
\hline & Sig. (2-tailed) & .000 & \\
\hline & $\mathrm{N}$ & 155 & 155 \\
\hline
\end{tabular}

**. $\mathrm{P}<0.01$

\section{Perbincangan}

Dapatan statistik diskriptif menunjukkan bahawa kepuasan kerja dan kualiti perkhidmatan dalaman masing- masing mempunyai tahap yang tinggi. Melalui kajian ini didapati bahawa tahap kepuasan kerja dan kualiti perkhidmatan dalaman adalah pada tahap yang tinggi iaitu masing-masing mempunyai nilai min 5.80 dan 5.91. Ini justeru membuktikan bahawa pemboleh ubah ini perlu dikaji dengan lebih mendalam kerana dikenalpasti mempunyai hubungan saling interaksi. Berdasarkan kajian lalu, di Malaysia masih kurang lagi kajian yang mengkaji pemboleh ubah ini khususnya dalam organisasi sukan.

Hasil dapatan analisis hubungan antara faktor kepuasan kerja dengan kualiti perkhidmatan dalaman menunjukkan bahawa terdapat hubungan yang signifikan pada tahap yang kuat dan positif. Ini membuktikan bahawa faktor kepuasan kerja ini mempunyai perkaitan yang sangat kuat $(\mathrm{r}=0.817, \mathrm{p}=0.00)$ dengan kualiti perkhidmatan dalaman. Keadaan ini adalah selari dengan dapatan Conduit dan Mavondo (2001) yang mana menunjukkan bahawa terdapat hubungan yang positif antara kualiti perkhidmatan dalaman dengan kepuasan kerja. Menurut kajian tersebut, pengekalan pelanggan dalam sesebuah organisasi adalah berkait rapat dengan kepuasan kerja yang dipengaruhi oleh tahap kualiti perkhidmatan yang disediakan oleh unit dalaman dalam sesebuah organisasi tersebut.

Selain daripada itu, Billy et al., (2006) dalam kajiannya dari sektor yang berbeza iaitu industri perhotelan antarabangsa juga mendapati bahawa aspek kepuasan kerja ini mampu mempengaruhi kualiti perkhidmatan dalaman dalam sesebuah organisasi tersebut. Ini secara tidak langsung membuktikan bahawa terdapat korelasi yang signifikan antara kepuasan kerja dengan kuaiti perkhidmatan dalaman. Untuk mengukuhkan lagi dapatan ini, kajian yang dilaksanakan oleh Ostroff (1992) mengenalpasti bahawa staf organisasi yang mempunyai kepuasan kerja yang tinggi lazimnya cenderung untuk lebih bersifat efektif justeru menbentuk kualiti perkhidmatan dalaman dan luaran yang lebih baik. Dalam kajian literatur bagi perkhidmatan pemasaran pula, kebanyakkan pengkaji mendapati dapatan yang menyokong pandangan bahawa organisasi yang menyediakan kualiti perkhidmatan dalaman yang baik kepada pelanggan dalaman pada umumnya berjaya dan kepuasan kerja juga dapat menghasilkan peningkatan dalam prestasi organisasi. 
Gould-Williams (2003) dalam kajiannya menyatakan bahwa apabila staf sesebuah organisasi bekerja dengan tekun dan mempunyai prestasi yang cemerlang, maka prestasi sesebuah organisasi akan dipengaruhi secara positif. Keadaan ini turut disokong oleh kajian terdahulu yang dikaji oleh beberapa pengkaji yang turut mendapati bahawa terdapat korelasi yang positif antara kepuasan kerja dengan prestasi organisasi (Chan et al., 2000; Chandrasekar, 2011; Ellinger et al., 2002; Harter, Schmidt, \& Hayes, 2002; Huselid, 1995; Koys, 2001; Schneider, Hanges, Smith, \& Salvaggio, 2003; Zohir, 2007). Hal ini kerana, Harter et al., (2002) mendapati korelasi positif antara penglibatan kepuasan kerja dan prestasi organisasi lazimnya diukur dengan produktiviti, keuntungan, perolehan pekerja, dan kepuasan pelanggan. Oleh itu, implikasi dapatan kajian menunjukkan bahawa dengan adanya kajian ini maka pihak pengurusan dalam sesebuah organisasi dapat lebih menfokuskan kepada elemen atau aspek yang akan mempengaruhi kepuasan kerja staf agar kualiti perkhidmatan dalaman adalah dalam keadaan yang terkawal justeru mempengaruhi peningkatan prestasi dalam sesebuah organisasi.

\section{Kesimpulan}

Kepuasan kerja dalam sesebuah organisasi dan kualiti perkhidmatan dalaman adalah sangat penting dan signifikan dengan keadaan tempat kerja pada masa kini tidak kira sama ada dalam sektor sukan atau bukan sukan. Hal ini kerana dengan meneliti faktor kepuasan kerja dan kualiti perkhidmatan dalaman ini, para pengkaji dan pihak pengurusan sumber manusia dalam sesebuah organisasi dapat memahami fungsi untuk menyokong perubahan kepada sesebuah organisasi bagi mendapatkan ganjaran yang diperoleh daripada pelaburan seterusnya menyumbang kepada perkembangan sesebuah organisasi tersebut. Oleh itu, pegawai sumber manusia dan individu yang bertanggungjawab khususnya pemimpin bagi sesebuah organisasi sukan tersebut perlu lebih peka dengan faktor yang akan mempengaruhi faktor kepuasan kerja dan kualiti perkhidmatan dalaman ini agar dapat melihat semula dasar dan keperluan sesebuah organisasi untuk memantapkan lagi sistem pengurusan dengan menitikberatkan faktor-faktor peramal yang dikaji agar kualiti perkhidmatan dalaman dapat diperbaiki dan dipertingkatkan.

Secara kesimpulannya, aspek kepuasan kerja dalam kalangan staf khususnya Majlis Sukan Negeri perlu dikaji dengan lebih terperinci kerana aspek ini merupakan salah satu aspek psikologi yang mampu mempengaruhi peningkatan kualiti perkhidmatan dalaman sesebuah organisasi. Kepuasan kerja dipercayai mempunyai hubung kait dengan tingkah laku seseorang individu dalam sesebuah organisasi. Oleh itu, bagi meningkatkan kepuasan kerja staf dalam Majlis Sukan Negeri, maka pihak pengurusan organisasi perlu memberi perhatian kepada aspek yang akan mempengaruhi kepuasan kerja ini agar dapat membuat penambahbaikan untuk menghasilkan tahap hubungan yang lebih positif antara kepuasan pekerja dengan kualiti perkhidmatan dalaman dalam sesebuah organisasi tersebut bagi menyumbang kepada keuntungan dan kejayaan jangka masa panjang sesebuah organisasi.

\section{Rujukan}

Arbeit, S., (1976). Selling jobs in the service sector. Business Horizons, 9 (3).

Adey, N. H., dan Bahari, F. H. (2010). Hubungan Antara Kecerdasan Emosi, Kepuasan Kerja dan komitmen terhadap orgnisasi. Jurnal Kemanusiaan, 16, 62-82.

Affendi, F. (2014). Tahap kepuasan kerja dan komitmen organisasi dalam kalangan guru kolej vokasional: pendekatan structural equation model (Doctoral dissertation, Universiti Tun Hussein Onn Malaysia). 
Amirtash Ali Mohammad, Mozaffari Syed Amir Ahmad, B. N. (2012). The relationship between organizational learning culture and job satisfaction and Internal service quality in sport organizations in Iran. European Journal of Experimental Biology, $4(2), 1220-1225$.

Back, K.-J., Lee, C.-K., \& Abbott, J. (2011). Internal Relationship Marketing: Korean Casino Employees' Job Satisfaction and Organizational Commitment. Cornell Hospitality Quarterly, 52(2), 111-124.

Barnes, B. R., \& Morris, D. S. (2000). Revising quality awareness through internal marketing: An exploratory study among French and English medium-sized enterprise. Total Quality Management, 11, 473-483.

Billy, B., Pearl, B.K., Gail, S., Skip, S. (2006). Job satisfaction, organizational commitment, and internal service quality: a case study of Las Vegas hotel/Casino industry. Journal of Human Resources in Hospitality \& Tourism 5 (2),37-54.

Caruana, A. \& Pitt, L. (1997). INTQUAL - an internal measure of service quality and the link between service quality and business performance. European Journal of Marketing. 31(8), 604-616.

Chan, K. C., Gee, M. V., \& Steiner, T. L. (2000). Employee happiness and corporate Financial performance. Financial Practice and Education, 10, 47-52.

Chandrasekar, K. (2011). Workplace environment and its impact on organizational performance in public sector organizations. International Journal of Enterprise Computing and Business Systems, 1, 1-16.

Chelladuraie P, (2003). Motivation performance of sport organization staff. Journal of sport management. 18: 73 -82.

Cook, S. (2004). Measuring customer service effectiveness. Burlington, VT: Gower Publishing Company.

Conduit, J. \& Mavondo, F.T. (2001), "How critical is internal customer orientation to market

Creswell, J. W. (2002). Research design: Qualitative, quantitative, and missed methods approaches. Thousand Oaks, CA: Sage Publications. (2008)

Daud, N. (2010). Jaminan Kerja dan Hubungannya dengan Kepuasan Kerja dan Komitmen Terhadap Organisasi.

Di Xie M.S (2005), Exploring Organizational Learning Culture, Job Satisfatcion Motivation to Learn, Organizational Commitment and Internal Service Quality In A Sport Organizational; The Ohio State Unviersity

Ellinger, A. D., Ellinger, A. E., Yang, B., \& Howton, S. W. (2002). The relationship between the learning organization concept and firm's financial performance: An empirical assessment. Human Resource Development Quarterly, 13, 5-22.

Faridahwati, M. S. (2006). Organisational Misbehavior. Akademika, 69, 57-82.

Ghorbani, A. \& Yarimoglu, E. K. (2014). E-Service Marketing. In A. Ghorbani (Ed.), Marketing in the Cyber Era: Strategies and Emerging Trends (pp. 1-8). IGI Global: USA.

Gilbert, G. R. (2000). Measuring Internal Customer Satisfaction. Managing Service Quality, $10(3), 178-186$.

Gotzami, K. D. \& Tsiotras G. D. (2002). The True Motives behind ISO 9000 Certification: Their Effect on the Overall Certification Benefits and the Long-term Contribution Towards TQM. International Journal of Quality \& Reliability Management. 19(2): 151-169.

Gould-Williams, J. (2003). The importance of HR practices and workplace trust in achieving superior performance: A study of public-sector organizations. The International Journal of Human Resource Management, 14, 28-54. 
Griffin, R.W. and Moorhead, G. (2013). Organizational Behavior: Managing People and Organizations, 11th ed., South-Western, Mason, OH.

Gunawardane, G. (2009). Relationship between Dimensions of Internal Service Quality and The Nature of The Internal Service Encounter-A Study In The Health Care Industry California Journal of Operations Management, 7(1), 21-30.

Hallowell, R., Schlesinger, L. A., \& Zornitsky, J. (1996). Internal Service Quality, Customer and Job Satisfaction: Linkages and Implications for Management. Human Resource Planning, 19, 20-31.

Harter, J. K., Schmidt, F. L., \& Hayes, T. L. (2002). Business-unit level relationship between employee satisfaction, employee engagement, and business outcomes: A metaanalysis. Journal of Applied Psychology, 87, 268-279.

Heskett, J. L., Sasser, W. E., \& Schlesinger, L. A. (1997). Service profit chain: Simon and Schuster.com.

Huselid, M. A. (1995). The impact of human resource management practices on turnover, productivity, and corporate financial performance. Academy of Management Journal, $38,635-672$.

Jun, M., \& Cai, S. (2010). Examining the Relationships between Internal Service Quality and its Dimensions, and Internal Customer Satisfaction. Total Quality Management \& Business Excellence, 21(2), 205-223.

Koys, D. J. (2001). The effects of employee satisfaction, organizational citizenship behavior, and turnover on organizational effectiveness: a unit-level, longitudinal study. Personnel Psychology, 54, 101-114.

Krejcie, V. R., \& Morgan. W.D (1970). Determining Sample Size for Research Activities, Educational and Psychological Measurement, (30), Duluth: University of Minnesota.

Kuei, C.-H. (1999). Internal Service Quality-An Empirical Assessment. International Journal of Quality \& Reliability Management, 16(8), 783-791.

Large, R. O., \& Konig, T. (2009). A gap model of purchasing's internal service quality: Concept, case study and internal survey. Journal of Purchasing \& Supply Management, 15, 25-32.

Liang Wang G, (2010). A Study of How the Internal-Service Quality of International Tourist Hotels Affects Organizational Performance: Using Employees' Job Satisfaction as the Mediator. University of Science and Technology, Taiwan.

Lok, P. dan Crawford, J. (2004). The effect of organizational culture and leadership style on job satisfaction and organizational commitment: A cross national comparison. Journal of Management Development, 23 (4), 321-338.

Marshall, G. W., Baker, J., \& Finn, D. W. (1998). Exploring Internal Customer Service Quality. Journal of Business \& Industrial Marketing, 13(4/5), 381-392.

McManus, I., Keeling, A., \& Paice, E. (2004). Stress, burnout and doctors' attitudes to work are determined by personality and learning style: A twelve-year longitudinal study of UK medical graduates. BMC medicine, 2(1), 29.

Miguel, P. A. C., Salomi, G. E., \& Abackerli, A. J. (2006b). Assessing Internal Service by Measuring Quality Dimensions in a Manufacturing Company. Paper presented at the Third International Conference on Production Research, America

Newman, K., Maylor, U. and Chansarkar, B. (2001) The nurse retention, quality of care and patient satisfaction chain. International Journal of Heath Care Quality Assurance 14 (2): $57-68$.

Ostroff, C. (1992). The relationship between satisfaction, attitudes, and performance: An organizational level analysis. Journal of Applied Psychology, 77, 963-974.

Panjakajornsak, V. (2012). Applying the service profit chain to a private hospital in Thailand. NIDA Development Journal: วารสาร พัฒนบริหารศาสตร์, 49(2), 79-108. 
Pantouvakis, A. (2011). Internal service quality and job satisfaction synergies for performance improvement: Some evidence from a B2B environment. Journal of Targeting, Measurement and Analysis for Marketing, 19(1), 11-22.

Porsoltani H, Iraji R, (2012). The relation between Organizational socialization and Job Satisfaction in Khorasn Razavimain Physical Education office employees in 2010. Journal of Sport Management and Motor Behavior.15: 79-96.

Prabha Ramseook-Munhurrun, Perunjodi Naidoo, Soolakshna D. Lukea-Bhiwajee (2009). Employee perceptions of service quality in a call centre. Managing Service Quality: An International Journal 19:5, 541-557.

Sagie, A., (1998). Employee absenteeism, organizational commitment, and job satisfaction: Another look. Journal of Vocational Behavior, 52 (2), 156-171. Sasser, W.E. \&

Schneider, B., Hanges, P. J., Smith, D. B., \& Salvaggio, A. N. (2003). Which comes first: Employee attitudes or organizational financial and market performance? Journal of Applied Psychology, 88, 836-851.

Spector, P. E. (1997). Job Satisfaction: Application, Assessment, Causes, and Consequences (Vol. 3): Sage.

Yue-Xia C, (2009). Examining how the quality of internal services affects customer satisfaction: Taking the example of local tax agencies in Eastern Taiwan. MA Inservice Master's Program. Graduate Institute of Public Administration. National Dong Hwa University. Taiwan.

Yusoff, M. K., (2012). Pendekatan Program Kualiti Kehidupan Bekerja (KKB). Dicapai Ogos 2017, daripada md kamal yusoff: http://mdkamalyusoff.blogspot.com

Zhen-You, C. (2003). How leadership styles, motives of achievement and their fitness affect the quality of internal services: Taking the example of marketing \& promotional staff at Taiwanese record labels, MA, Graduate Institute of Communication Management, Ming Chuan University.

Zohir, S. C. (2007). Role of Dhaka export processing zone: Employment and empowerment. Research Report, Bangladesh Institute of Development Studies, Dhaka, People's Republic of Bangladesh. 